\title{
Transition Metal Complexes of Naproxen: Synthesis, Characterization, Forced Degradation Studies, and Analytical Method Verification
}

\author{
Md. Sharif Hasan, ${ }^{1}$ Ruhul Kayesh, ${ }^{2}$ Farida Begum, ${ }^{1}$ and S. M. Abdur Rahman ${ }^{1}$ \\ ${ }^{1}$ Department of Clinical Pharmacy and Pharmacology, University of Dhaka, Dhaka 1000, Bangladesh \\ ${ }^{2}$ Department of Pharmaceutical Chemistry, University of Dhaka, Dhaka 1000, Bangladesh \\ Correspondence should be addressed to S. M. Abdur Rahman; smarahman@du.ac.bd
}

Received 20 September 2015; Accepted 12 November 2015

Academic Editor: Guido Crisponi

Copyright (C) $2016 \mathrm{Md}$. Sharif Hasan et al. This is an open access article distributed under the Creative Commons Attribution License, which permits unrestricted use, distribution, and reproduction in any medium, provided the original work is properly cited.

\begin{abstract}
The aim of our current research was to synthesize some transition metal complexes of Naproxen, determine their physical properties, and examine their relative stability under various conditions. Characterizations of these complexes were done by 1H-NMR, Differential Scanning Calorimetry (DSC), FT-IR, HPLC, and scanning electron microscope (SEM). Complexes were subjected to acidic, basic, and aqueous hydrolysis as well as oxidation, reduction, and thermal degradation. Also the reversed phase high-performance liquid chromatography (RP-HPLC) method of Naproxen outlined in USP was verified for the Naproxenmetal complexes, with respect to accuracy, precision, solution stability, robustness, and system suitability. The melting points of the complexes were higher than that of the parent drug molecule suggesting their thermal stability. In forced degradation study, complexes were found more stable than the Naproxen itself in all conditions: acidic, basic, oxidation, and reduction media. All the HPLC verification parameters were found within the acceptable value. Therefore, it can be concluded from the study that the metal complexes of Naproxen can be more stable drug entity and offer better efficacy and longer shelf life than the parent Naproxen.
\end{abstract}

\section{Introduction}

Compounds with metals as therapeutic agents for various diseases states have been investigated in the last few decades [1-3]. Metals can react with different atoms of many amino acids residues in proteins providing therapeutic actions [4]. Because of their different mechanism of actions, the development of metal complexes for various drugs provides an alternative route of novel drug delivery system [5]. Binding of a drug to metalloelement can enhance or reduce its activity and in some cases the complex may have even such activity that the parent compound does not have [6].

Nonsteroidal anti-inflammatory drugs (NSAIDs) are some of the most prescribed drugs worldwide as antipyretic, analgesic, and anti-inflammatory agents [7]. However, the major limitation to NSAID use is the gastric and intestinal mucosal damage [7]. In the UK an estimated 12000 peptic ulcer complications and 1200 deaths per year are attributable to NSAIDs use [8]. Therefore, much has been studied so far to reduce the gastric toxicity of NSAIDs and in this regard, complex formation of NSAIDs with transition metals has long been recognized as an effective way of reducing gastric mucosal lesions caused by these drugs [9]. Thus, the present study is performed to synthesize transition metal complexes of Naproxen (Figure 1), to resolve their characterization, and to observe their relative stability by conducting forced degradation studies. Forced degradation is an integral component of validating many analytical methods that indicate stability of the drug and detect different impurities coming from manufacturing processes $[10,11]$. They facilitate analytical methodology development and validation, better understanding of stability of drug molecules in different environments, and finding out the degradation pathways of drugs and byproducts [12-14]. 
<smiles>COc1ccc2cc([C@@H](C)C(=O)O)ccc2c1</smiles>

Figure 1: Chemical structure of Naproxen.

To the best of our knowledge, a combined study of synthesis, characterization, and forced degradation study of Naproxen-metal complexes has never been done yet. But completed studies of the degradation of the drug substance and drug product are required at the new drug application (NDA) stage. So in our current study we put our effort to synthesize and characterize different transition metalNaproxen complexes along with the determination of their relative stability under various stressed conditions. Also, the RP-HPLC method for analysis of Naproxen outlined in USP has been verified for the drug-metal complexes.

\section{Experimental}

2.1. Materials. All the apparatus and reagents were in analytical grade of Merck origin, used without purification, and were available in the laboratory of the Department of Clinical Pharmacy and Pharmacology, Faculty of Pharmacy, University of Dhaka.

2.2. Synthesis of Sodium Salt of Naproxen (HL). $0.82 \mathrm{gm}$ $(0.1 \mathrm{M})$ of Naproxen (ligand) was dissolved with $0.1 \mathrm{M}$ of sodium hydroxide solution in water to form the sodium salt of Naproxen. Then the solution was sonicated for 5 minutes and kept in room temperature. The potency of Naproxen must be considered before preparation. The reaction mixture was put on a water bath to evaporate until a crystal film appeared; upon cooling the white product separated out.

2.3. General Procedure for Synthesis of Transition Metal Complexes. Equimolar metal salts dissolved in water were added to the above mixture so that the ratio $n$ (metal): $n$ (ligand) of monovalent, divalent, and trivalent ions used was $1: 1,1: 2$ and $1: 3$, respectively, in each case and immediate precipitation occurred. Then the solid complexes were isolated by filtration, washed until being free of chlorides with the corresponding solvent (methanol or water), and finally dried at room temperature.

2.4. Analytical Methods. HPLC system (Shimadzu Prominence), equipped with UV-visible detector, was used for the analysis of the samples. LC-solutions software was used for recording data. Reversed phase C-18 column (Zorbax Eclipse $\mathrm{XBD}-\mathrm{C} 18,150 \times 4.6 \mathrm{~mm}, 5 \mu \mathrm{m})$ was used to analyze the standards and samples. The HPLC assay method described in United States Pharmacopoeia (USP35 NF30, volume 3, Page 3996,2012 ) was used to analyze the samples.
TABLE 1: Types of degradation reactions and conditions.

\begin{tabular}{ll}
\hline Degradation reaction & Typical conditions \\
\hline Elevated temperature & Exposed to $105^{\circ} \mathrm{C}$ heat, up to 3 hours \\
Acid hydrolysis & Treated with $1 \mathrm{~N} \mathrm{HCl}$ up to 24 hours \\
Base hydrolysis & Treated with $1 \mathrm{~N} \mathrm{NaOH}$ up to 24 hours \\
Oxidation & $\begin{array}{l}\text { Treated with } 10 \% \mathrm{H}_{2} \mathrm{O}_{2} \text { solution up to } \\
24 \text { hours }\end{array}$ \\
Reduction & $\begin{array}{l}\text { Treated with } 10 \% \mathrm{Na} \text { bisulfite solution } \\
\text { up to } 24 \text { hours }\end{array}$ \\
Water hydrolysis & Treated with water up to 24 hours \\
\hline
\end{tabular}

2.5. Forced Degradation Conditions. It is important that more strenuous conditions than those used for accelerated studies $\left(25^{\circ} \mathrm{C} / 60 \% \mathrm{RH}\right.$ or $\left.40^{\circ} \mathrm{C} / 75 \% \mathrm{RH}\right)$ should be used while performing this study. In general, the following conditions were investigated: (1) acid and base hydrolysis, (2) hydrolysis at various $\mathrm{pH},(3)$ thermal degradation, (4) photolysis, and (5) oxidation. It was focused on determining the conditions that degrade the drug by approximately $10 \%$. However, beginning at extreme conditions $\left(80^{\circ} \mathrm{C}\right.$ or even higher, $0.5 \mathrm{~N} \mathrm{NaOH}$, $0.5 \mathrm{~N} \mathrm{HCl}, 3 \% \mathrm{H}_{2} \mathrm{O}_{2}$ ) and testing at shorter (2 hours, 5 hours, 8 hours, 24 hours, etc.) multiple time points allow for a rough evaluation of degradation rate. The conditions listed in Table 1 were followed in the current study [15].

2.6. Acid Hydrolysis. $1 \mathrm{mg} / \mathrm{mL}$ of solutions was prepared of each Naproxen-metal chelates. Then $1 \mathrm{~mL}$ of sample solutions and $4 \mathrm{~mL}$ of $1 \mathrm{M} \mathrm{HCl}$ were mixed and mixture was kept for 24 hours at room temperature. After 24 hours, the sample solutions were allowed to be neutralized by $1 \mathrm{M} \mathrm{NaOH}$ to pH 7.0 and the volume was made up to $10 \mathrm{~mL}$ with diluting solution. The prepared samples were then analyzed on HPLC.

2.7. Basic Hydrolysis. $1 \mathrm{mg} / \mathrm{mL}$ of solutions was prepared of each Naproxen-metal chelates. Then $1 \mathrm{~mL}$ of sample solutions and $4 \mathrm{~mL}$ of $1 \mathrm{M} \mathrm{NaOH}$ were mixed and mixture was kept for 24 hours at room temperature. After 24 hours, the sample solutions were allowed neutralized by $1 \mathrm{M} \mathrm{HCl}$ to $\mathrm{pH} 7.0$ and the volume was made up to $10 \mathrm{~mL}$ with diluting solution. The prepared samples were then analyzed on HPLC.

2.8. Oxidation. Oxidation of Naproxen and its metal complexes was studied using $10 \% \mathrm{H}_{2} \mathrm{O}_{2}$ for 24 hours. $1 \mathrm{~mL}$ of samples and $9 \mathrm{~mL}$ of $10 \% \mathrm{H}_{2} \mathrm{O}_{2}$ solution were mixed and the mixture was kept for 24 hours at room temperature. After 24 hours, the sample solutions were analyzed.

2.9. Reduction. Reduction of Naproxen and its metal complexes was studied using 10\% Sodium bisulfite for 24 hours. $1 \mathrm{~mL}$ of samples and $9 \mathrm{~mL}$ of $10 \%$ Sodium bisulfite solution were mixed and the mixture was kept for 24 hours at room temperature. After 24 hours, the sample solutions were analyzed. 
TABLE 2: Physical, analytical, and thermal properties of metal complexes.

\begin{tabular}{lcccccccc}
\hline Compound & \multirow{2}{*}{ Formula } & $\begin{array}{c}\text { Formula } \\
\text { weight }\end{array}$ & Color & \multicolumn{2}{c}{$\begin{array}{c}\text { Yield } \\
\%(\mathrm{~g})\end{array}$} & \multicolumn{2}{c}{ Analysis (\%) calculated (found) } & \multicolumn{2}{c}{$\begin{array}{c}\text { Melting } \\
\text { point }\left({ }^{\circ} \mathrm{C}\right)\end{array}$} \\
\hline$\left(\mathrm{C}_{14} \mathrm{H}_{13} \mathrm{O}_{3}\right)_{2} \mathrm{Cu} \cdot 2 \mathrm{H}_{2} \mathrm{O}$ & $\mathrm{C}_{28} \mathrm{H}_{30} \mathrm{O}_{8} \mathrm{Cu}$ & 558.07 & Green & 84.7 & $60.21(60.08)$ & $5.38(5.32)$ & $11.39(11.42)$ & 227.51 \\
$\left(\mathrm{C}_{14} \mathrm{H}_{13} \mathrm{O}_{3}\right)_{2} \mathrm{Co} \cdot 2 \mathrm{H}_{2} \mathrm{O}$ & $\mathrm{C}_{28} \mathrm{H}_{30} \mathrm{O}_{8} \mathrm{Co}$ & 553.45 & Light red & 75.8 & $60.71(60.39)$ & $5.42(5.45)$ & $10.65(10.67)$ & 242.62 \\
$\left(\mathrm{C}_{14} \mathrm{H}_{13} \mathrm{O}_{3}\right)_{3} \mathrm{Fe} \cdot 3 \mathrm{H}_{2} \mathrm{O}$ & $\mathrm{C}_{42} \mathrm{H}_{45} \mathrm{O}_{12} \mathrm{Fe}$ & 797.63 & Yellow & 86.3 & $63.19(63.12)$ & $5.64(5.63)$ & $7.00(6.97)$ & 235.13 \\
$\left(\mathrm{C}_{14} \mathrm{H}_{13} \mathrm{O}_{3}\right) \mathrm{Ag} \cdot \mathrm{H}_{2} \mathrm{O}$ & $\mathrm{C}_{14} \mathrm{H}_{15} \mathrm{O}_{4} \mathrm{Ag}$ & 355.13 & White & 85.3 & $47.30(47.22)$ & $4.26(4.22)$ & $30.38(30.41)$ & 218.89 \\
$\left(\mathrm{C}_{14} \mathrm{H}_{13} \mathrm{O}_{3}\right)_{2} \mathrm{Zn} \cdot 2 \mathrm{H}_{2} \mathrm{O}$ & $\mathrm{C}_{28} \mathrm{H}_{30} \mathrm{O}_{8} \mathrm{Zn}$ & 559.9 & White & 78.3 & $60.01(59.78)$ & $5.36(5.32)$ & $11.68(11.73)$ & 225.28 \\
\hline
\end{tabular}

2.10. Water Hydrolysis. $1 \mathrm{~mL}$ of samples and $9 \mathrm{~mL}$ of distilled water were mixed and the mixture was kept for 24 hours at room temperature. After 24 hours, the sample solutions were analyzed.

2.11. Dry Heat Degradation. $5 \mathrm{mg}$ of each Naproxen-metal chelate was placed in an oven for 3 hours at $105^{\circ} \mathrm{C}$ and then the heated samples were dissolved in $5 \mathrm{~mL}$ of diluting solution and allowed to attain the room temperature. The prepared samples were then suitably diluted and analyzed.

2.12. Analytical Method Verification. The analytical method was verified according to United States of Pharmacopeia (USP) 37, General Information, 1225, Validation of Compendial Procedures guideline with respect to some parameters used in method validation. According to 21 CFR 211.194(a)(2) of the current Good Manufacturing Practice regulations, "suitability of all compendia testing methods used shall be verified under actual conditions of use" (USP 37, General Information $/\langle 1226\rangle$ Verification of Compendial Procedures). In current case, system suitability, solution stability, accuracy, precision, and robustness were performed for method verification.

\section{Result and Discussion}

3.1. Physical, Analytical, and Thermal Properties. All the complexes synthesized were crystalline solids and soluble in common organic solvents but insoluble in ethanol and acetone. They were characterized by elemental analyses, IR spectra, thermal analysis, electronic photography (SEM), and magnetic properties (NMR). Table 2 shows the results of elemental and thermal analysis of the complexes. The melting points or decomposition temperatures of the chelates are higher which suggests their thermal stability. Naproxen decomposes at $153^{\circ} \mathrm{C}$ where the complexes decompose in the range of $218-250^{\circ} \mathrm{C}$ (Figure $2(\mathrm{a})$ ) followed by complete burning at above $700^{\circ} \mathrm{C}$. The representative equations for the formation of the complexes can be presented as

$$
\begin{aligned}
& \mathrm{M}^{n+} \mathrm{Cl}_{n} \cdot h \mathrm{H}_{2} \mathrm{O}+n \mathrm{NaL} \\
& \quad=\mathrm{ML}_{n} \cdot m \mathrm{H}_{2} \mathrm{O}+n \mathrm{NaCl}+(h-m) \mathrm{H}_{2} \mathrm{O}
\end{aligned}
$$

(where $\mathrm{M}=\mathrm{Co}, \mathrm{Cu}, \mathrm{Zn}, \mathrm{Ag}, \mathrm{Fe} ; n=1$ or 2 or $3 ; h=0,2,4$, or $6 ; m=0$ or 2 or 3 ).

\begin{tabular}{|c|c|c|c|c|}
\hline \multirow{2}{*}{ Compound } & \multicolumn{3}{|c|}{$v_{\text {as }}\left(\mathrm{COO}^{-}\right)$} & \multirow{2}{*}{$v\left(\mathrm{H}_{2} \mathrm{O}\right)$} \\
\hline & $\nu_{\mathrm{as}}$ & $v_{s}$ & $\Delta v$ & \\
\hline $\mathrm{NaL}$ & 1545 & 1409 & 136 & - \\
\hline $\mathrm{CuL}_{2} \cdot 2 \mathrm{H}_{2} \mathrm{O}$ & 1554 & 1405 & 149 & 3406 \\
\hline $\mathrm{CoL}_{2} \cdot 2 \mathrm{H}_{2} \mathrm{O}$ & 1562 & 1415 & 147 & 3418 \\
\hline $\mathrm{FeL}_{3} \cdot 3 \mathrm{H}_{2} \mathrm{O}$ & 1601 & 1449 & 142 & 3422 \\
\hline $\mathrm{AgL} \cdot \mathrm{H}_{2} \mathrm{O}$ & 1610 & 1451 & 159 & 3388 \\
\hline $\mathrm{ZnL}_{2} \cdot 2 \mathrm{H}_{2} \mathrm{O}$ & 1544 & 1412 & 132 & 3386 \\
\hline
\end{tabular}

TABLE 3: Infrared data $\left(\mathrm{cm}^{-1}\right)$ of Naproxen-metal complexes in $\mathrm{KBr}$.

3.2. FTIR Spectra. In this study, the carboxylic acid group of Naproxen shows the $v(\mathrm{C}=\mathrm{O})$ stretching mode as a band at $v=1729 \mathrm{~cm}^{-1}$. This was gone because of deprotonation and in the sodium salt there were two new bands at 15351546 and 1405-1414 range, the carboxylate antisymmetric and symmetric vibrations, respectively (Figures 2(b) and $2(\mathrm{c}))$. The coordination of the carboxylate ion to metal ion took place in three different ways [16]. The difference between $v_{\text {as }}(\mathrm{COO})$ and $\nu_{\mathrm{s}}(\mathrm{COO})$ in monodentate complexes was expected to be greater than $350 \mathrm{~cm}^{-1}$. When $200<$ $\Delta v<350 \mathrm{~cm}^{-1}$, anisobidentate was observed which means an intermediate state between monodentate and bidentate and when $\Delta v<200 \mathrm{~cm}^{-1}$, the carboxylate groups were regarded as bidentate [16]. These situations were observed in the relative position of the antisymmetric and symmetric stretching vibrations. The main IR bands in the spectra of the sodium salt and the complexes are listed in Table 3. There was a band observed in the region 3145-3455 which is certainly due to the absorption of crystal or coordination water. Assignment of the carboxylate group of these metal complexes coordination depended on the position of both $\nu_{\text {as }}$ and $v_{s}$ bands and the values of $\Delta v$ [17-21]. The values of all of these complexes lie in the range of $132-159 \mathrm{~cm}^{-1}$ which is close to that of sodium salt of Naproxen indicating that the carboxylate group acts as a bridging ligand. In solid state, the synthesized complexes of carboxylate mostly form bridged dimers $\left(\mathrm{M}_{2} \mathrm{~L}_{2}\right.$ or $\left.\mathrm{M}_{2} \mathrm{~L}_{4}\right)$ and also polymeric networks [22].

3.3. NMR Spectra. In the ${ }^{1} \mathrm{H}-\mathrm{NMR}$ spectrum of Naproxen, the protons of methyl $\left(\mathrm{CH}_{3}\right)$ group have a sharp doublet at $\sim \delta 1.5-1.6$; the methenyl $(-\mathrm{CH})$ proton has a triplet around $\delta 3.60-3.90$. In case of the methoxy $\left(\mathrm{CH}_{3} \mathrm{O}\right)$ protons, they exhibit a sharp singlet at $\delta 4.00$ and the naphthyl protons 


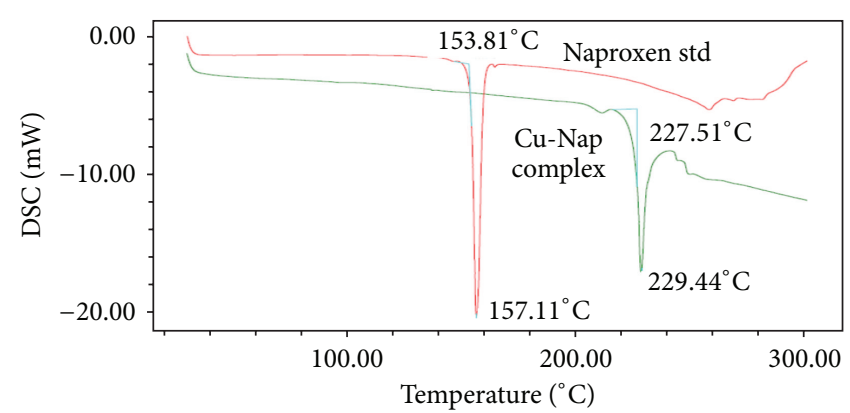

(a)

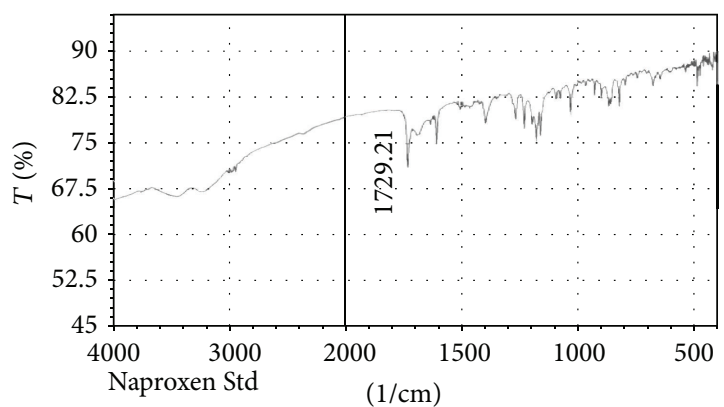

(b)

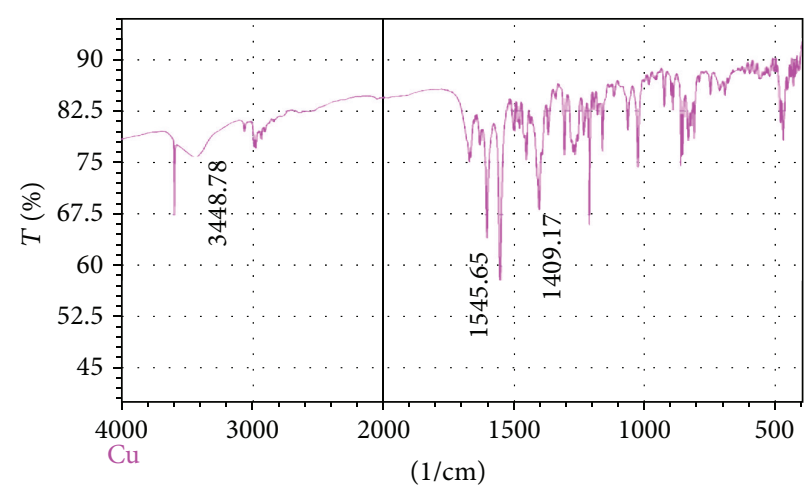

(c)

FIGURE 2: (a) DSC thermogram of Naproxen and its Copper complex: (b) and (c) IR spectrum of Naproxen and its Copper complex, respectively.

appear at $\delta 7.10-7.80$ as a multiplet. Sequentially all of these protons shift upfield in complexes; the methenyl proton displays the highest shift $\delta 0.25-0.30$, whereas the methoxy protons shift the least $\sim \delta 0.05$. This occurs because of the lesser electron withdrawing capacity of metal ions in the complexes relative to that of the carboxy proton in the ligand. The hydrogen atom of the $-\mathrm{COOH}$ group is absent in the metal complexes of ${ }^{1} \mathrm{H}$-NMR spectra (range of 10-13 ppm). This data indicates coordination and the carboxyl group is not protonated and the complexation reaction takes place.

3.4. Scanning Electron Microscopy. Scanning electron microscope (SEM) images were taken in order to study the surface morphology of Naproxen-metal complexes. The SEM micrographs of ligand and its complexes are shown in Figure 3. The images showed particles with fiber-like morphology of the complexes compared to ligand (Naproxen) which is homogenously distributed in the solid powder. The photograph clearly indicated that the complexes are hydrated and they formed dimer or even polymeric networks in micrometer range.

3.5. Characterization by HPLC. The RP-HPLC studies were performed in order to determine identity of the new synthetic products in comparison to the free ligand with respect to retention time. Acetonitrile and water in various ratios were used as mobile phases. HPLC methods were used to confirm
TABLE 4: Retention times of the complexes and their ligands.

\begin{tabular}{lc}
\hline Compound & Retention time $\left(t_{r}\right)(\mathrm{min})$ \\
\hline Naproxen (ligand) & 4.442 \\
Naproxen-Copper complex $(\mathrm{N}-\mathrm{Cu})$ & 4.353 \\
Naproxen-Cobalt complex $(\mathrm{N}-\mathrm{Co})$ & 4.336 \\
Naproxen-Iron complex $(\mathrm{N}-\mathrm{Fe})$ & 4.388 \\
Naproxen-Silver complex $(\mathrm{N}-\mathrm{Ag})$ & 4.424 \\
Naproxen-Zinc complex $(\mathrm{N}-\mathrm{Zn})$ & 4.388 \\
\hline
\end{tabular}

the appearance of new products after the synthesis had been performed. The samples of ligand and complexes eluted close to each other with similar retention times (Figure 4). The chromatographic data for the complexes and free ligand are given in Table 4.

3.6. Stability Profile. In the forced degradation study it was found that Naproxen-metal complexes were the most stable compounds against any type of forced degradation condition applied than parent Naproxen. The highest degradation of Naproxen was found by acid hydrolysis and it was only 7.92\%. Among the complexes, Naproxen-Iron complex was found most stable against the stressed conditions. Degradation levels are very close among all these complexes and it is due to the almost same coordination environment of the complexes. The most probable reason for their higher stability 


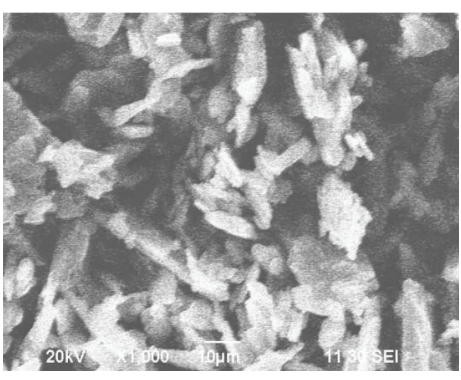

(a)

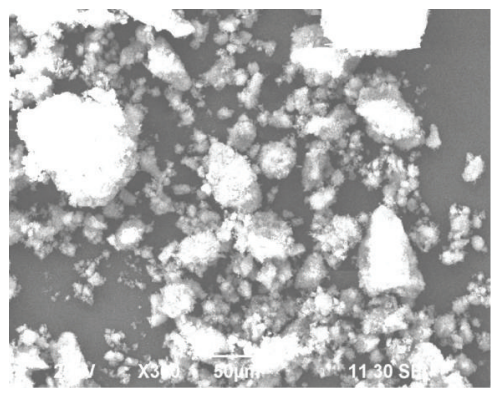

(d)

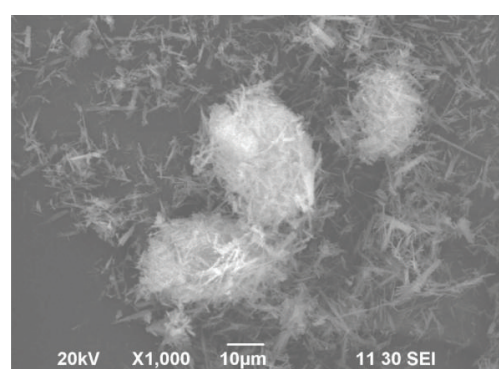

(b)

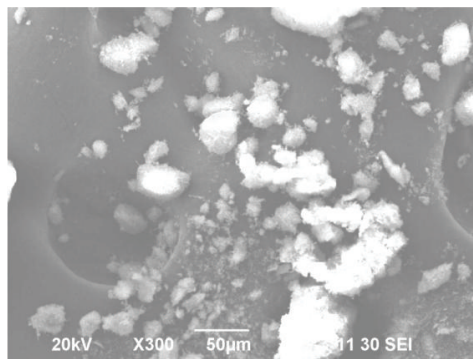

(e)

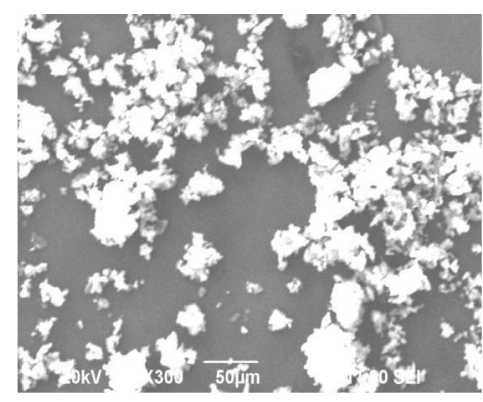

(c)

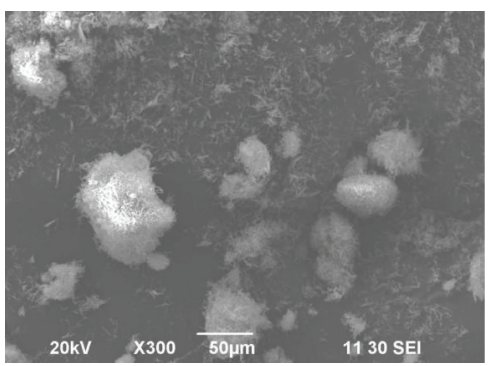

(f)

FIGURE 3: Scanning electron microscopy (SEM) photomicrograph of (a) Naproxen, (b) Naproxen-Copper complex, (c) Naproxen-Cobalt complex, (d) Naproxen-Iron complex, (e) Naproxen-Silver complex, and (f) Naproxen-Zinc complex, respectively.

TABLE 5: Degradation profile of Naproxen and its metal chelates.

\begin{tabular}{|c|c|c|c|c|c|c|}
\hline Tested compounds & $\begin{array}{l}\% \text { of loss in } \\
\text { acid media }\end{array}$ & $\begin{array}{l}\% \text { of loss in } \\
\text { basic media }\end{array}$ & $\begin{array}{c}\% \text { of loss in } \\
\text { oxidation }\end{array}$ & $\begin{array}{l}\% \text { of loss in } \\
\text { reduction }\end{array}$ & $\begin{array}{c}\% \text { of loss in water } \\
\text { hydrolysis }\end{array}$ & $\begin{array}{c}\% \text { of loss in } \\
\text { dry heat }\end{array}$ \\
\hline Naproxen & 7.92 & 4.76 & 6.99 & 7.31 & 1.39 & 5.03 \\
\hline Nap-Cu complex & 3.59 & 2.48 & 2.12 & 2.13 & 0.29 & 3.50 \\
\hline Nap-Co complex & 2.13 & 1.99 & 2.98 & 2.55 & 0.31 & 3.07 \\
\hline Nap-Fe complex & 3.75 & 1.72 & 1.68 & 1.86 & 0.01 & 2.65 \\
\hline Nap-Ag complex & 4.36 & 3.57 & 4.71 & 3.29 & 0.18 & 4.18 \\
\hline Nap-Zn complex & 2.50 & 2.26 & 2.02 & 2.42 & 0.05 & 3.78 \\
\hline
\end{tabular}

than Naproxen is the possibility of forming dimer or even polymer structures that is shown in SEM images. In DSC study, it was also revealed that the complexes have very high decomposition point than that of the parent Naproxen. That is why they are able to show better stability against stressed condition. The results were summarized in Table 5 and in Figures 5 and 6.

\subsection{Method Verification Study}

3.7.1. System Suitability Test. All parameters were found within the limit. Results were summarized in Table 6.

3.7.2. Solution Stability. Area changes were investigated up to three consecutive days. Low quantity of $\%$ RSD of area changes demonstrated that the drugs were fairly stable in the diluting solution and in the mobile phase. Results were shown in Table 7.
TABLE 6: System suitability parameters.

\begin{tabular}{lcc}
\hline Parameter & Naproxen (free ligand) & USP limit [23] \\
\hline Tailing factor $(T)$ & 0.899 & $T \leq 2$ \\
Theoretical plates $(N)$ & 2834.541 & $N \geq 2000$ \\
\% RSD of retention time & 0.075 & $\% \mathrm{RSD} \leq 2.0 \%$ \\
\% RSD of peak area & 0.094 & \% RSD $\leq 2.0 \%$ \\
\hline
\end{tabular}

3.7.3. Accuracy and Precision. Accuracy or recovery study was performed and result found in acceptable range for all samples for different concentrations. The range of the acceptability for accuracy was $97.0-103.0 \%$.

The \%RSD values found in precision study depicted in Table 8 showed that the compendial method provides acceptable intra- and interday variations for samples. 


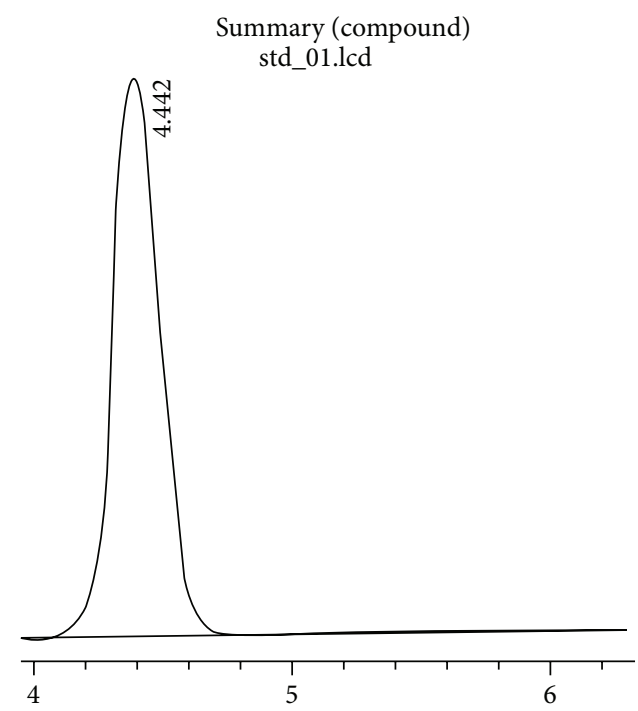

(a)

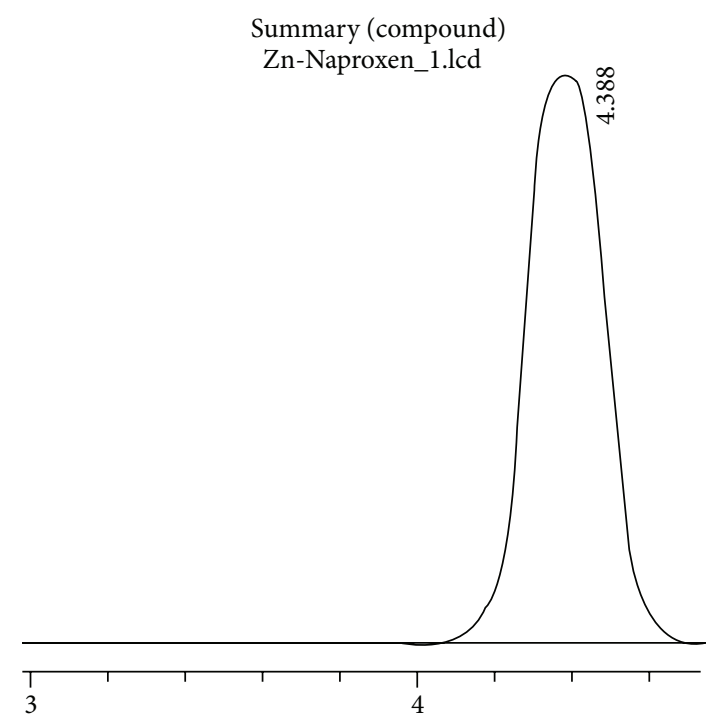

(c)

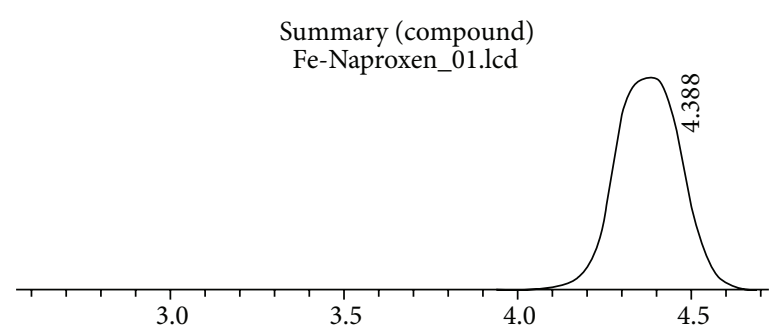

(e)

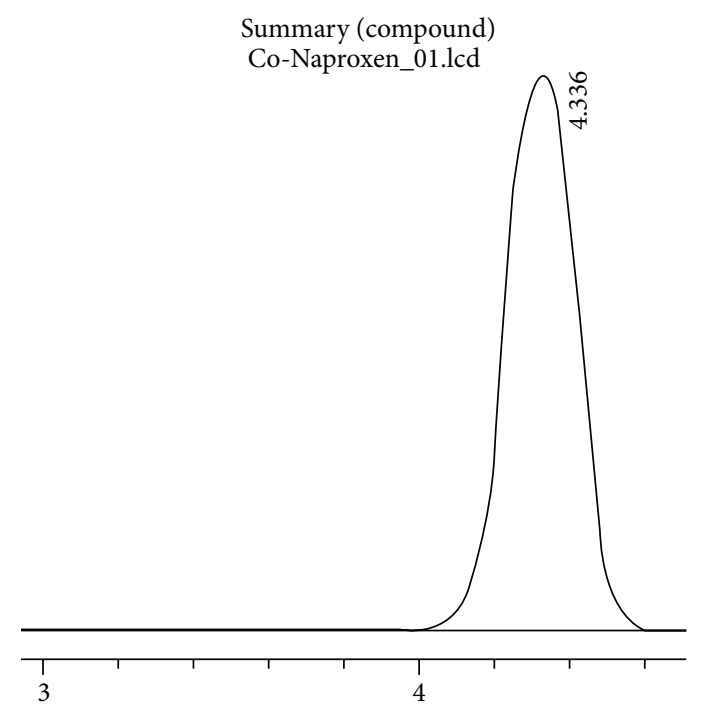

(b)

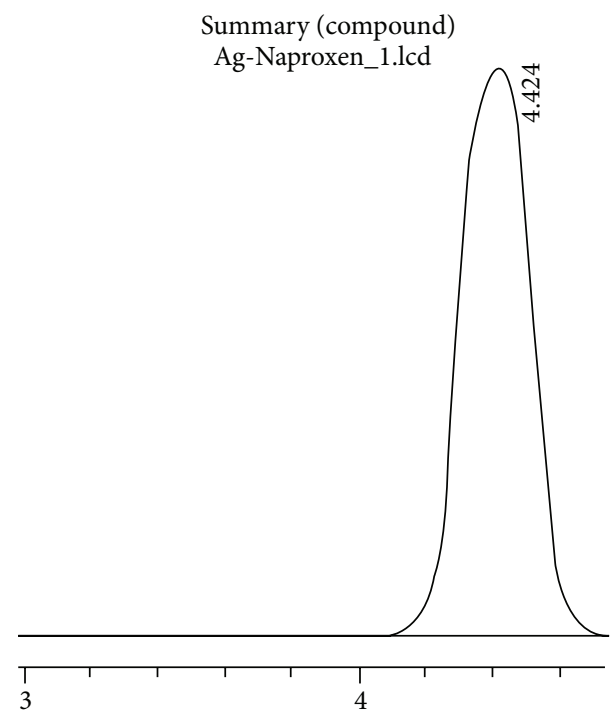

(d)

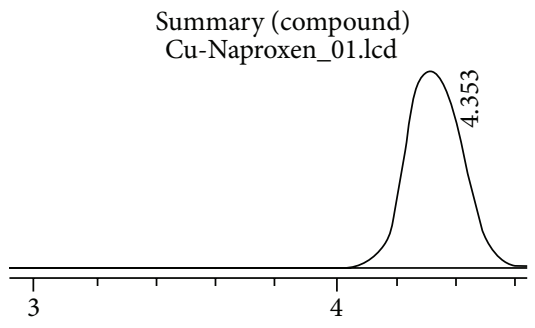

(f)

Figure 4: HPLC chromatograms of (a) Naproxen, (b) Naproxen-Cobalt complex (N-Co), (c) Naproxen-Zinc complex (N-Zn), (d) NaproxenSilver complex (N-Ag), (e) Naproxen-Iron complex (N-Fe), and (f) Naproxen-Copper complex (N-Cu), respectively.

3.7.4. Robustness. Predetermined variations were performed under the experimental conditions to assess their robustness. We changed $\mathrm{pH} \pm 0.2$, flow rate $\pm 50 \%$, wave length $\pm 3 \mathrm{~nm}$, and solvent concentration $\pm 30 \%$. Results were shown in Table 9 . No significant changes were found.

\section{Conclusion}

Search for drugs of higher efficacy and lower toxicity is a never ending effort. In our current research we were able to synthesize some Naproxen-metal derivatives and 


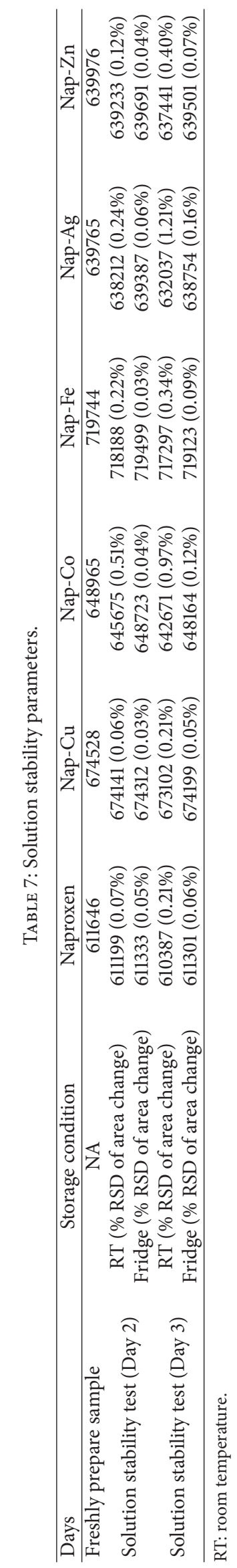


TABLE 8: Accuracy and precision parameters.

\begin{tabular}{lccccccc}
\hline Parameters & Limit & Naproxen & Nap-Cu & Nap-Co & Nap-Fe & Nap-Ag & Nap-Zn \\
\hline Accuracy & $97.0-103.0 \%$ & $98.95-100.11$ & $99.34-99.87$ & $98.45-99.24$ & $98.45-101.45$ & $99.45-101.37$ & $99.55-102.62$ \\
Precision (intraday) & \% RSD $\leq 2$ & 0.812 & 0.522 & 0.657 & 0.729 & 0.478 & 0.835 \\
& Day 1 & 0.974 & 0.745 & 1.135 & 1.256 & 0.875 & 0.435 \\
Precision (interday) & Day 2 & 0.486 & 0.467 & 0.409 & 1.145 & 1.155 & 1.479 \\
& Day 3 & 1.134 & 1.324 & 1.421 & 1.678 & 1.137 & 1.231 \\
Different analyst and & \% RSD $\leq$ 3 (interday) & 1.342 & 1.421 & 1.241 & 1.289 & 1.123 \\
instruments & & & & & &
\end{tabular}

TABLE 9: Robustness of the method.

\begin{tabular}{|c|c|c|c|c|}
\hline Parameter & Samples & Retention time (min) & Tailing factor & Theoretical plate \\
\hline \multirow{6}{*}{$\begin{array}{l}\text { Flow rate } \\
( \pm 50 \%) \\
(n=3)\end{array}$} & Naproxen & $3.121-6.675$ & $0.564-1.134$ & $2536-3002$ \\
\hline & $\mathrm{Nap}-\mathrm{Cu}$ & $2.858-7.456$ & $0.637-1.046$ & $2535-3257$ \\
\hline & Nap-Co & $2.936-7.136$ & $0.635-1.145$ & $2504-2993$ \\
\hline & Nap-Fe & $3.012-6.546$ & $0.537-1.267$ & $2245-2866$ \\
\hline & Nap-Ag & $2.789-7.245$ & $0.563-1.046$ & $2536-3658$ \\
\hline & Nap-Zn & $2.977-6.896$ & $0.682-1.035$ & $2546-3527$ \\
\hline \multirow{6}{*}{$\begin{array}{l}\text { Solvent ratio } \\
( \pm 30 \%) \\
(n=3)\end{array}$} & Naproxen & $3.234-6.789$ & $0.456-1.464$ & $2454-3013$ \\
\hline & Nap-Cu & $3.567-5.346$ & $0.523-1.368$ & $2575-2935$ \\
\hline & Nap-Co & $3.786-5.359$ & $0.684-1.257$ & $2576-2896$ \\
\hline & Nap-Fe & $3.008-5.289$ & $0.473-1.147$ & $2689-3035$ \\
\hline & Nap-Ag & $3.678-6.149$ & $0.568-1.427$ & $2736-3024$ \\
\hline & Nap-Zn & $3.789-7.899$ & $0.564-1.139$ & $2524-3467$ \\
\hline \multirow{6}{*}{$\begin{array}{l}\mathrm{pH} \text { of buffer } \\
\text { solution } \\
( \pm 0.2) \\
(n=3)\end{array}$} & Naproxen & $3.934-4.567$ & $0.836-0.956$ & $2890-3205$ \\
\hline & $\mathrm{Nap}-\mathrm{Cu}$ & $4.003-4.678$ & $0.845-0.899$ & $2600-3765$ \\
\hline & Nap-Co & $3.612-4.568$ & $0.786-0.876$ & $2535-3402$ \\
\hline & Nap-Fe & $3.613-4.257$ & $0.823-0.956$ & $2546-3867$ \\
\hline & Nap-Ag & $3.583-4.945$ & $0.726-0.915$ & $2394-3957$ \\
\hline & Nap-Zn & $3.993-4.456$ & $0.736-0.925$ & $2356-2895$ \\
\hline \multirow{6}{*}{$\begin{array}{l}\text { Detector } \\
\text { wave length } \\
( \pm 3 \mathrm{~nm}) \\
(n=3)\end{array}$} & Naproxen & $4.346-4.467$ & $0.823-0.913$ & $2536-3406$ \\
\hline & $\mathrm{Nap}-\mathrm{Cu}$ & $4.456-4.789$ & $0.823-0.834$ & $2675-3177$ \\
\hline & Nap-Co & $4.345-4.456$ & $0.864-0.900$ & $2465-2794$ \\
\hline & Nap-Fe & $4.412-4.467$ & $0.789-0.822$ & 2575-2904 \\
\hline & Nap-Ag & $4.367-4.467$ & $0.844-0.878$ & $2356-3602$ \\
\hline & Nap-Zn & $4.367-4.419$ & $0.812-0.901$ & 2531-3387 \\
\hline \multirow{6}{*}{$\begin{array}{l}\text { Temperature } \\
\left( \pm 10^{\circ} \mathrm{C}\right) \\
(n=3)\end{array}$} & Naproxen & $4.324-4.456$ & $0.823-8.678$ & $2567-2958$ \\
\hline & Nap-Cu & $4.326-4.567$ & $0.746-8.134$ & $2296-3042$ \\
\hline & Nap-Co & $4.324-4.467$ & $0.783-0.899$ & $2515-3657$ \\
\hline & Nap-Fe & $4.389-4.498$ & $0.823-0.843$ & $2549-3208$ \\
\hline & Nap-Ag & $4.358-4.418$ & $0.823-0.845$ & $2285-3647$ \\
\hline & Nap-Zn & $4.329-4.475$ & $0.813-0.843$ & $2576-3102$ \\
\hline
\end{tabular}

to highlight their stability profile under stressed conditions with a view to facilitating the invention of novel NSAIDs with better therapeutic efficacy. Lower toxicity of Naproxen in terms of gastric irritation has been established earlier. But from the result of present study further useful information was achieved that the metal derivatives of Naproxen were found more stable than Naproxen itself. This finding suggests that the metal derivatives of Naproxen can be more potent anti-inflammatory agent in human body with longer half-life as well as in the dosage 


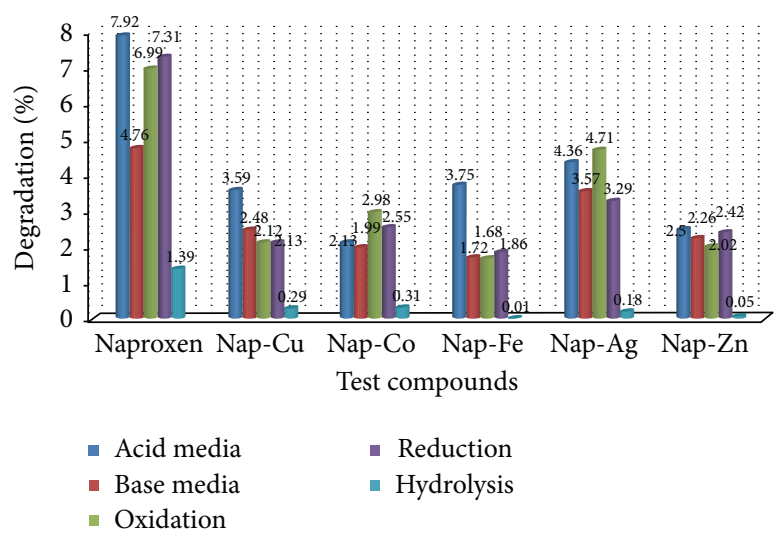

FIGURE 5: Graphical presentation of liquid state degradation of Naproxen-metal chelates.

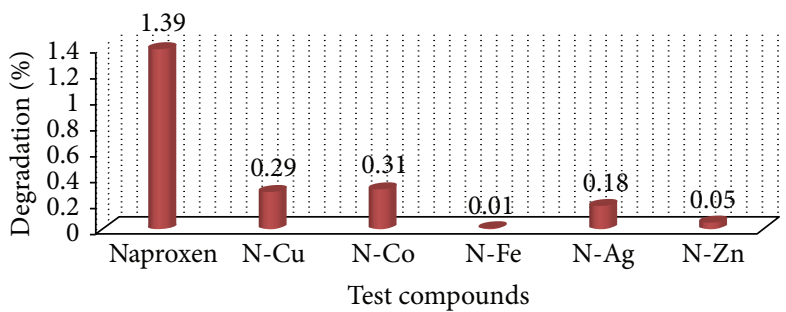

FIGURE 6: Graphical presentation of dry heat degradation of Naproxen-metal chelates.

form with longer shelf life when compared to the parent Naproxen.

\section{Conflict of Interests}

The authors declare no conflict of interests.

\section{Authors' Contribution}

The study was carried out in collaboration among all the authors. The idea was developed by Md. Sharif Hasan. The analyses were done by Md. Sharif Hasan and Ruhul Kayesh. Ruhul Kayesh wrote the first draft of the manuscript and arranged the references which were edited and finalized by Md. Sharif Hasan.

\section{Acknowledgments}

Md. Sharif Hasan and Ruhul Kayesh are very grateful to Dr. S. M. Abdur Rahman and Farida Begum for their administrative support, guidance, and reviewing paper.

\section{References}

[1] C. G. Hartinger and P. J. Dyson, "Bioorganometallic chemistry-from teaching paradigms to medicinal applications," Chemical Society Reviews, vol. 38, no. 2, pp. 391-401, 2009.

[2] M. Navarro, "Gold complexes as potential anti-parasitic agents," Coordination Chemistry Reviews, vol. 253, no. 11-12, pp. 16191626, 2009.
[3] M. J. Clarke, "Ruthenium metallopharmaceuticals," Coordination Chemistry Reviews, vol. 236, no. 1-2, pp. 209-233, 2003.

[4] C.-M. Che and F.-M. Siu, "Metal complexes in medicine with a focus on enzyme inhibition," Current Opinion in Chemical Biology, vol. 14, no. 2, pp. 255-261, 2010.

[5] I. Kostova and G. Momekov, "New zirconium (IV) complexes of coumarins with cytotoxic activity," European Journal of Medicinal Chemistry, vol. 41, no. 6, pp. 717-726, 2006.

[6] F. A. Adekunle, J. A. O. Woods, O. O. E. Onawumi, and O. A. Odunola, "Synthesis and characterization of nickel(II) complexes of various substituted acid hydrazides," Asian Journal of Chemistry, vol. 22, no. 7, pp. 5543-5550, 2010.

[7] J. G. Hardman, L. E. Limbird, and A. G. Gilman, Goodman \& Gilman's the Pharmacological Basis of Therapeutics, McGrawHill, New York, NY, USA, 10th edition, 2001.

[8] C. J. Hawkey, "Non-steroidal anti-inflammatory drug gastropathy: causes and treatment," Scandinavian Journal of Gastroenterology, vol. 31, supplement 220, pp. 124-127, 1996.

[9] S. Rafique, M. Idrees, A. Nasim, H. Akbar, and A. Athar, "Transition metal complexes as potential therapeutic agents," Biotechnology and Molecular Biology Reviews, vol. 5, no. 2, pp. 38-45, 2010.

[10] ICH Guidance for Industry, Q1A Stability Testing of New Drug Substances and Products, ICH-Q1A, 2001.

[11] FDA Guidance for Industry, Analytical Procedures and Methods Validation: Chemistry, Manufacturing, and Controls Documentation, Draft Guidance, FDA, 2000.

[12] FDA, "International conference on harmonization: stability testing of new drug substances and products," Federal Register, vol. 59, no. 183, pp. 48753-48759, 1994.

[13] FDA, "International Conference on Harmonization: Draft Revised Guidance on Q1A(R) Stability Testing of New Drug 
Substances and Products," Federal Register, vol. 65, no. 78, pp. 21446-21453, 2000, ICH Q1A(R).

[14] FDA, "Draft guidance for industry, stability testing of drug substances and drug products," Federal Register, vol. 63, no. 109, pp. 31224-31225, 1998, Combination of ICH Q1A-Q1C and Q5C, draft.

[15] D. W. Reynolds, K. L. Facchine, J. F. Mullaney, K. M. Alsante, T. D. Hatajik, and M. G. Motto, "Available guidance and best practices for conducting forced degradation studies," Pharmaceutical Technology, vol. 26, no. 2, pp. 48-56, 2002.

[16] L. Tian, Y. Sun, H. Li et al., "Synthesis, characterization and biological activity of triorganotin 2-phenyl-1,2,3-triazole4-carboxylates," Journal of Inorganic Biochemistry, vol. 99, no. 8, pp. 1646-1652, 2005.

[17] L. P. Battaglia, A. B. Corradi, G. Marcotrigiano, L. Menabue, and G. C. Pellacani, "Synthesis and spectroscopic and structural properties of bis( $\mathrm{N}$-acetyl-DL-tryptophanato)copper(II) complex and its amine adducts. Effect of amines on the amino acid coordination. Crystal and molecular structure of diaquabis $(N$ acetyl-DL-tryptophanato)bis(pyridine)copper(II)," Journal of the American Chemical Society, vol. 102, no. 8, pp. 2663-2669, 1980.

[18] L. P. Battaglia, A. B. Corradi, G. Marcotrigiano, L. Menabue, and G. C. Pellacani, "Copper(II) complexes of nitrogenprotected amino acids: synthesis and spectroscopic, magnetic, and structural properties of bis $(N$-acetyl- $\beta$ alaninato)diaquacopper(II) and tetrakis $[\mu$ - $(N$-acetyl- $\beta$ alaninato)]-diaquadicopper(II) dihydrate. A case of structural isomerism," Inorganic Chemistry, vol. 20, no. 4, pp. 1075-1080, 1981.

[19] L. Antolini, L. Menabue, G. C. Pellacani et al., "Magnetic and spectroscopic properties of dimeric copper(II) complexes of $N$ benzyloxycarbonyl-substituted amino acid anions," Journal of the Chemical Society, Dalton Transactions, no. 10, pp. 2325-2326, 1984.

[20] D. Miernik, M. D. Cieślak-Golonka, and Z. A. Szulc, "Communication the first examples of the coordination ability of 9-OXO10 -acridineacetic ion, an important interferon inducer," Journal of Coordination Chemistry, vol. 20, no. 2, pp. 203-207, 1989.

[21] N. B. Behrens, G. M. Diaz, and D. M. L. Goodgame, "Metal complexes of the antibiotic nalidixic acid," Inorganica Chimica Acta, vol. 125, no. 1, pp. 21-26, 1986.

[22] M. I. Azocar, H. Muñoz, P. Levin, N. Dinamarca, G. Gómezet, A. Ibañez et al., "Synthesis and characterization of silver(I) complexes with ligands having anti-inflammatory properties," Communications in Inorganic Synthesis, vol. 1, no. 1, pp. 19-21, 2013.

[23] United States Pharmacopeia (USP) 34 (NF 29), Chapter 621, 2011. 

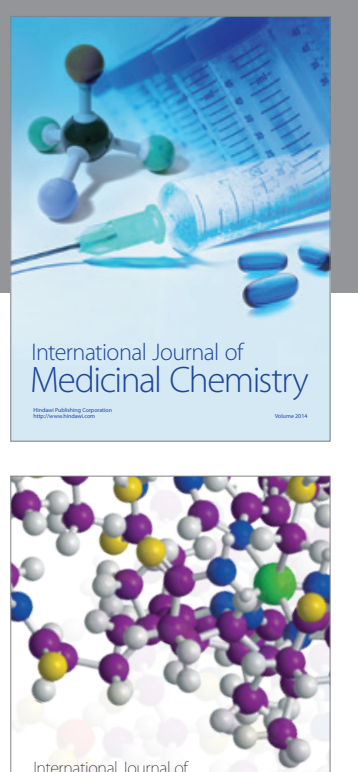

Carbohydrate Chemistry

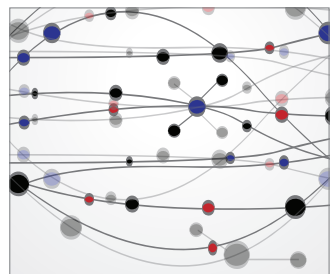

The Scientific World Journal
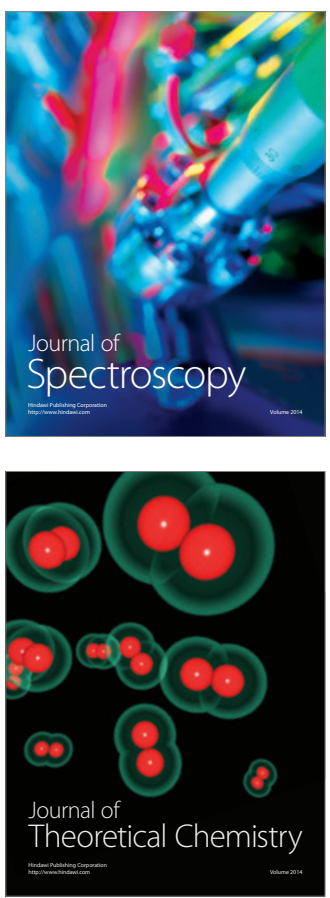
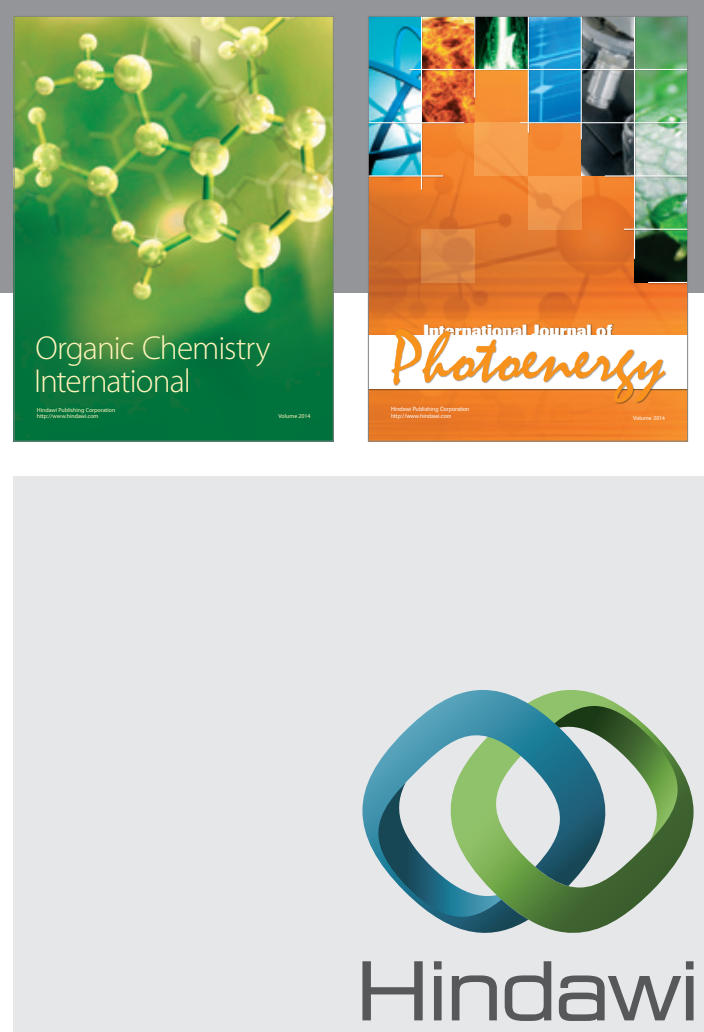

Submit your manuscripts at

http://www.hindawi.com

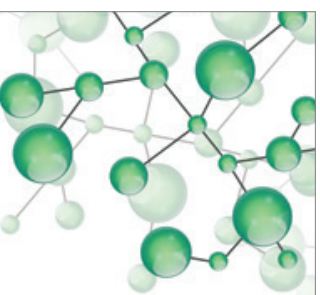

International Journal of

Inorganic Chemistry

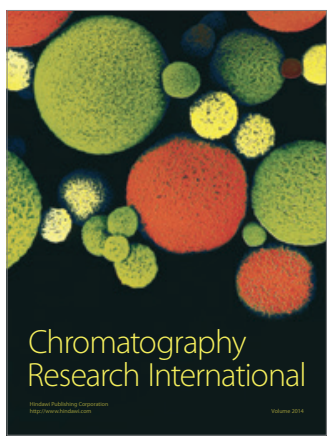

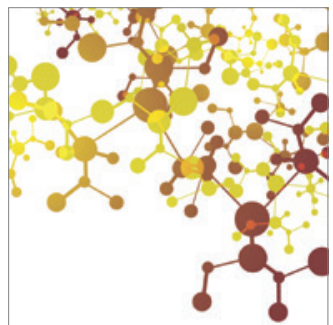

Applied Chemistry
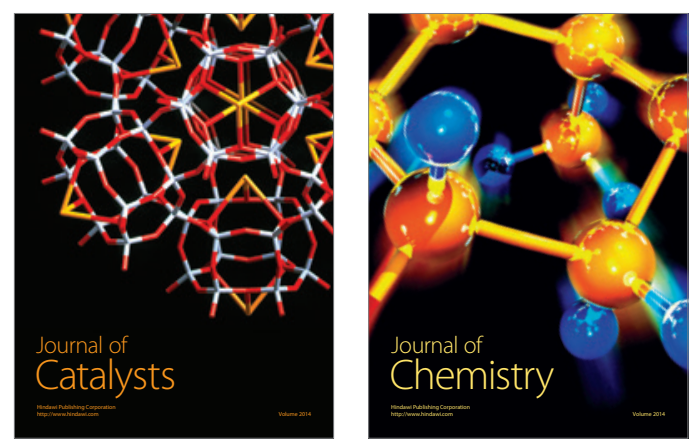
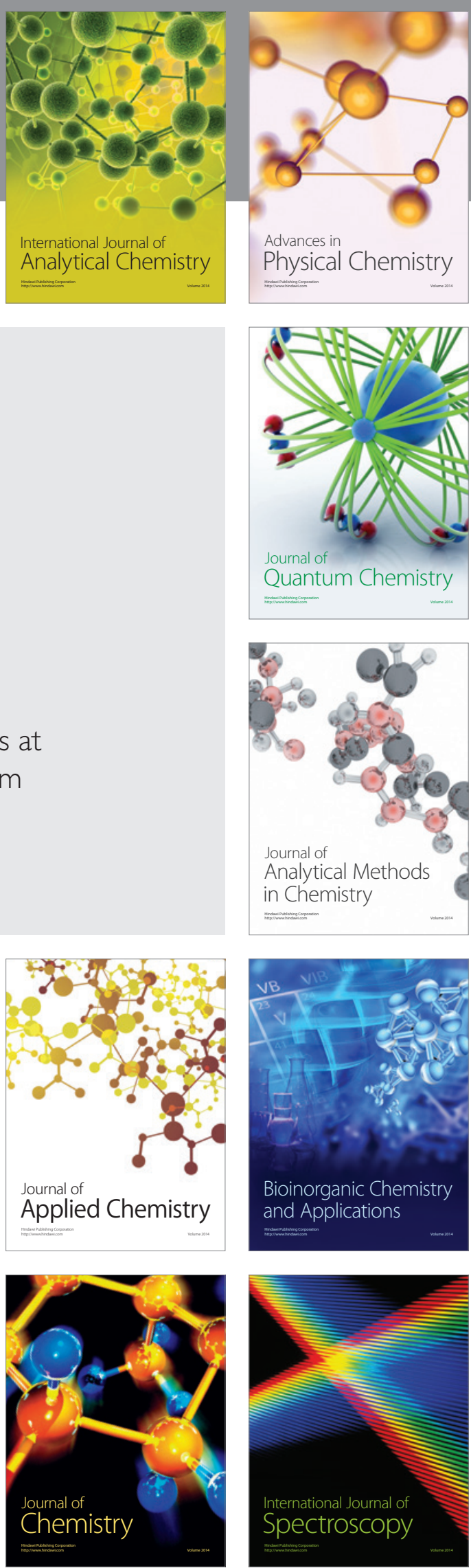